\title{
Correspondence
}

\section{Psychiatry in Africa}

Cine The Royal College of Psychiatrists is about - to pilot a project for psychiatry specialist registrars to spend 3 months working in Africa as part of their training. In April 2006, I attended the African Psychiatric Association and Allied Professional Conference 'Mental Health in Africa: Time for Action', in Addis Ababa, Ethiopia, on behalf of the College. While attending the conference, I was asked to look at the feasibility of registrars working in an African country such as Ethiopia.

The number of professional psychiatrists in African countries is very low, which creates a need for the training of more nurses and health workers in basic and practical methods for assessing patients and providing treatment. At the conference a repeated suggestion was to use traditional healers as part of an integrated mental health service, as this would represent a pragmatic, low-cost, psychosocial, communitybased approach.

Ethiopia is five times the size of the UK and has a population of approximately 75 million. There are 14 psychiatrists in the country, who all work in the capital, where there is one psychiatric hospital, with 360 beds. The first psychiatry training programme was established in 2003 between the Universities of Addis Ababa and Toronto. The University of Toronto has provided contextually relevant mental health education 3 months a year to seven Ethiopian doctors, who were due to complete the full programme in July 2006.

In further discussions with several local psychiatrists, it was agreed that a specialist registrar in Ethiopia could be well utilised in a supervisory teaching capacity, focusing on complementing the existing didactic teaching by developing clinical skills, providing psychotherapy supervision and problem-based learning, presenting at journal clubs and developing presentation skills and expertise in the use of information technology. The post holder could visit regional centres and supervise staff there, and might also have the opportunity to supervise research and encourage audit. If such placements were of longer duration, say of 6-12 months, this would minimise registrars draining local resources and they could be in a position to facilitate visits by other UK psychiatrists for shorter periods.

Such a programme would also offer significant benefits to the UK in terms of specialist registrars developing managerial skills, managing limited resources more innovatively and developing awareness of cultural issues, which would be relevant when returning to work, particularly in areas with large diasporic populations.

Dr Jonathan Campion Specialist Registrar on St George's Psychiatry Training Scheme, London, UK

\section{International recruitment: a Pakistani perspective}

Sir:

Chaturvedi, in his article entitled 'What is important for quality of life of psychiatrists?' (International Psychiatry, vol. 3, no. 2, April 2006, p. 20), raised some important issues in relation to the international recruitment of psychiatrists from India. He highlighted the fact that there are unfavourable aspects of work in India for psychiatrists and that an opportunity to work in a high-income country can benefit doctors. Here, I wish to relate the situation in Pakistan.

First, the law and order situation in Pakistan has now deteriorated to such an extent that personal safety is not guaranteed: there are frequent bomb blasts, suicide bombings, lootings and kidnappings. Some psychiatrists have been threatened and have left the country on the advice of the security services.

With such a huge population and so few psychiatrists, psychiatrists should be in high demand. However, this is not the case. In Pakistan, alternative practitioners see a large proportion of those who are mentally ill. General practitioners do see the majority of the patients, but their referral to specialist services is inhibited by the patients' reluctance to see a psychiatrist; hospital consultants also tend to look after the mental health of their patients, perhaps for similar reasons. The Pakistan Medical and Dental Council (PMDC) gives psychiatry low priority. There is therefore no pressure to recruit more psychiatrists.

As far as the public sector medical schools are concerned, active recruitment, despite vacancies, is not in evidence. There are several reasons for this: fear of loss of authority by the existing chiefs; posts being advertised only for rural areas; and various hidden agendas and political machinations. Furthermore, the private sector will be unable to provide employment for the psychiatrists being trained locally and those who are returning from abroad. In any case, the option of private practice is not always appealing. One has to have institutional support to build a bank of patients. Some non-governmental organisations run clinics but the remuneration is meagre.

Low pay scales in an era of high inflation is another factor that is a source of great dissatisfaction to psychiatrists. Moreover, it is strange, within public sector appointments, that a psychiatrist working in one province cannot apply for a job in another province.

Finally, exposure to sub-specialties is almost nonexistent.

The migration of a few psychiatrists would not cause any problem but could help them to advance professionally, and give them a better quality of life.

Dr Amin Muhammad Gadit Professor of Psychiatry, Memorial University of Newfoundland, Canada
Correspondence

is welcome on

any of the articles

or issues raised

in International

Psychiatry. Letters

of no more than

500 words should

be sent to

the Editor,

Hamid Ghodse,

email hghodse@

sgul.ac.uk 